\title{
BMJ Open Preventable emergency admissions of older adults: an observational mixed- method study of rates, associative factors and underlying causes in two Dutch hospitals
}

\author{
Steef van den Broek (D , ${ }^{1}$ Nikki Heiwegen, ${ }^{2}$ Margot Verhofstad, ${ }^{2}$ \\ Reinier Akkermans, ${ }^{3,4}$ Liselore van Westerop, ${ }^{1}$ Yvonne Schoon (D) , 2,5 \\ Gijs Hesselink (1) 2,4
}

To cite: van den Broek S, Heiwegen N, Verhofstad M, et al. Preventable emergency admissions of older adults: an observational mixed-method study of rates, associative factors and underlying causes in two Dutch hospitals. BMJ Open 2020;10:e040431. doi:10.1136/ bmjopen-2020-040431

- Prepublication history and additional material for this paper are available online. To view these files, please visit the journal online (http://dx.doi. org/10.1136/bmjopen-2020040431).

Received 14 May 2020 Revised 13 September 2020 Accepted 28 0ctober 2020

Check for updates

(C) Author(s) (or their employer(s)) 2020. Re-use permitted under CC BY-NC. No commercial re-use. See rights and permissions. Published by BMJ.

For numbered affiliations see end of article.

Correspondence to Dr Steef van den Broek; s.vandenbroek@cwz.nl

\section{ABSTRACT}

Objective Older adults are hospitalised from the emergency department (ED) without potentially needing hospital care. Knowledge about rates, associative factors and causes of these preventable emergency admissions (PEAs) is limited. This study aimed to determine the rates, associative factors and causes for PEAs of older adults.

Design A mixed-method observational study.

Setting The EDs of two Dutch hospitals.

Participants 492 patients aged $>70$ years and hospitalised from the ED.

Measurements Quantitative data were retrospectively extracted from the electronical medical record over a 1-month period. Admissions were classified (non) preventable based on a standardised approach. Univariate and multivariate multilevel logistic regression analyses were performed to identify possible associations between PEAs and demographic, clinical and care process factors. Qualitative data were prospectively collected by email and telephone interviews and analysed thematically to explore hospital physician's perceived causes for the identified PEAs.

Results Of the 492 included cases, 86 (17.5\%) were classified as PEA. Patients with a higher age (adjusted OR $1.04,95 \% \mathrm{Cl} 1.01$ to $1.08 ; p=0.04$ ), a low urgency classification (adjusted OR 1.89, 95\% Cl 1.14 to 3.15 ; $\mathrm{p}=0.01$ ), and attending the ED in the weekend (adjusted OR 2.02, $95 \% \mathrm{Cl} 1.22$ to $3.37 ; \mathrm{p}<0.01$ ) were associated with an increased likelihood of a PEA. 49 physicians were interviewed by telephone and email. Perceived causes for PEAs were related to patient's attitudes (eg, postponement of medical care at home), provider's attitudes (eg, deciding for admission after family pressure), health system deficiencies (eg, limited access to community services during out-of-hours and delayed access to inpatient diagnostic resources) and poor communication between primary care and hospital professionals about patient treatment preferences.

Conclusions Our findings contribute to existing evidence that many emergency admissions of older adults are preventable, thereby indicating a possible source of

\section{Strengths and limitations of this study}

- To our knowledge, this is the first study that assessed preventable emergency admission (PEA) rates, associated factors and physician's perceived causes at the individual older patient level.

- Findings show that many causes for PEAs of older adults exist at various levels (ie, patient, provider, emergency department, hospital, primary care and hospital-primary care interface), and that many causes are amendable for policy or managerial intervention.

- The factors associated with PEAs may be biased by the omission of confounding variables that were not included in our regression analyses.

- Including patient and community caregiver perspectives would have contributed to a more comprehensive and reliable understanding of causes for PEAs.

unnecessary expensive, and potentially harmful, hospital care.

\section{INTRODUCTION}

Demographic changes have led to a worldwide increase of older adults attending the emergency department (ED) and subsequent hospitalisations. ${ }^{1-4}$ The rise of hospital admissions after visiting the ED can be explained by the growing population of older adults requiring more frequent acute hospital care via the $\mathrm{ED}$ as the most common entry point to healthcare. ${ }^{12}$ However, it also raises concerns about whether all admissions of older adults from the ED (ie, emergency admissions) are necessary or could have been prevented.

Preventable emergency admissions (PEAs) are those considered to be preventable or avoidable through timely and effective primary care or outpatient care. ${ }^{5-7}$ PEAs 
are often estimated by the measurement of admissions caused by ambulatory care-sensitive conditions (ACSCs). ${ }^{8}$ Current literature suggests that the number of PEAs are substantial,,${ }^{9}{ }^{10}$ even though they may be overestimated because of insensitive measurements. ${ }^{10}{ }^{11}$ Preventable hospitalisation rates are especially high among frail older adults. ${ }^{12-14}$ These patients often attend the ED with atypical signs and multimorbidity which complicate clinical decision-making and the physician's decision to admit the patient or not. ${ }^{15}$ Apart from service provision in a resource-limited health system and high costs that could have been prevented, ${ }^{16-18}$ PEAs can also be harmful. Especially older adults are at a high risk for loss of ADL function and facing complications-after or during hospitalisation-such as delirium, malnutrition, dehydration, infections and falling. ${ }^{19-22}$ Reducing preventable admissions has therefore been a focus of policy-makers, commissioners and service providers for many years.

Despite awareness for the need to reduce PEAs of older adults, ${ }^{4} 121421$ insight lacks into the factors that help us predict and understand these admissions to happen. So far, research has mainly focused on finding possible associations between hospital admissions for ACSCs and sociodemographic (ie, deprivation, rurality, race), health system (ie, insurance coverage, access to services) and epidemiological (ie, prevalence of health problems and diseases) data in retrospective study designs at the regional or national level. ${ }^{5}{ }^{14} 23-28$ No studies have searched directly for risk factors or underlying causes for PEAs at the individual level of the older patient. By examining the social and clinical history of individual cases, and by exploring the clinical decision-making at the ED, we may be better able to identify PEAs of older adults. Moreover, we may better understand its associative factors and underlying causes, which may be amenable to policy or managerial intervention. The perspective of physicians involved in the decision-making process is thereby valuable input for understanding the context in which PEAs occur apart from the use of objective quantitative measures. ${ }^{29} 30$

Therefore, the aims of this study were to: (1) determine the prevalence of PEAs of older adults in two EDs, (2) to identify factors associated with PEAs and (3) to explore physicians' perceived causes of PEAs.

\section{METHODS \\ Design}

We performed a mixed methods observational study in two different EDs. We used quantitative data to determine the rates of PEAs and to identify associative factors, and qualitative data to explore possible causes for the identified PEAs.

\section{Setting}

The study was performed in the EDs of two hospitals in the urban region of Nijmegen in the middle-east of the Netherlands (online supplementary file 1). The Radboud
University Medical Center (Radboudumc) is a Dutch level 1 trauma centre with an annual census of 22000 ED visits, of which $26 \%$ are older adults. The Canisius-Wilhelmina (CWZ) hospital is a large regional hospital with an annual census of 27000 visits, of which $27 \%$ are older adults. Together, both EDs cover the prehospital emergency care in the Nijmegen region (approximately 350000 inhabitants). Both EDs are staffed by emergency medicine (EM) physicians and residents. They have admission privileges and usually discuss potential admissions with physicians on duty from other inpatient specialties. The EM physicians of both EDs are employed by the hospital and therefore have no financial gain in admitting patients.

\section{Data collection}

\section{Study sample and sampling}

For the period of 1 month (July and November 2018, respectively), patients were sampled consecutively in order of appearance. Patients were eligible if they: were aged 70 years or older and hospitalised from the ED. Patients with a high energetic trauma, admitted to the intensive care unit or transferred to another hospital were excluded from the study. Eligible candidates unwilling to participate in scientific research (expressed by a note in their medical chart) were excluded from the study as well. Patients attending the ED after being previously included were subsequently included as a new case. At both sites, residents with work experience in the ED (MV and SvdB) retrospectively extracted data on patient demographics, clinical factors and care process factors (see table 1 for all variables) from predefined information fields and notes made by physicians and nurses in the electronical medical record (EMR). Based on previous publications $^{24-62930}$ and our own professional experiences at the ED, we assumed that these factors may be associated with the professional's decision to admit a patient. ED referral was dichotomised into 'self' and 'by physician or ambulance'. Marital status was dichotomized into 'single' and 'partner/spouse'. Polypharmacy was dichotomised into less than and five or more different medicines. ${ }^{31} \mathrm{We}$ used the Charlson Comorbidity Index ${ }^{32}$ to determine the comorbidity level. We dichotomised ED arrival time into office hours (06:01 to 18:00) and out-of-office hours (18:01 to 06:00), and day of ED attendance into weekdays and weekend (ie, Friday 18:01 to Sunday 12:00)). The urgency triage level was dichotomised into 'low urgency' (U3-U5) and 'high urgency' (U1-U2) based on the urgency classification levels of the Netherlands Triage System (NTS). ${ }^{33}$

\section{Assessment of emergency admissions}

At both study sites, two residents (MV, NH, SvdB, $\mathrm{LvW}$ ) reviewed the clinical and process reports in the EMR of the included cases, and independently classified each admission as: 'preventable' or 'not preventable'. Admissions were considered preventable if at the time of admission: (1) no somatic causes were identified for the patient's initial problem, (2) no 
Table 1 Characteristics of included cases

\begin{tabular}{|c|c|}
\hline Characteristics & Total $(n=492)$ \\
\hline Age, mean years (SD) & $79.1(6.7)$ \\
\hline \multicolumn{2}{|l|}{ Sex } \\
\hline Male, n (\%) & $230(46.7)$ \\
\hline Female, n (\%) & $262(53.3)$ \\
\hline \multicolumn{2}{|l|}{ ED referral } \\
\hline By physician or ambulance, n (\%) & 349 (70.9) \\
\hline By patient self, n (\%) & $143(29.1)$ \\
\hline \multicolumn{2}{|l|}{ Urgency classification } \\
\hline High urgency*, n (\%) & $253(51.4)$ \\
\hline Low urgency†, n (\%) & 237 (48.2) \\
\hline Unknown, n (\%) & $2(0.4)$ \\
\hline \multicolumn{2}{|l|}{ Time of ED arrival } \\
\hline Office hoursł, n (\%) & $324(65.9)$ \\
\hline Out of hours§, n (\%) & $168(34.1)$ \\
\hline \multicolumn{2}{|l|}{ ED attendance } \\
\hline Weekdays, n (\%) & $361(73.4)$ \\
\hline Weekendף, n (\%) & $131(26.6)$ \\
\hline \multicolumn{2}{|l|}{ Polypharmacy $^{\star *}$} \\
\hline No, n (\%) & $106(21.5)$ \\
\hline Yes, n (\%) & $386(78.5)$ \\
\hline $\mathrm{CCl}$, mean (SD) & $5.96(2.2)$ \\
\hline ED length of stay, mean minutes (SD) & $223.5(96.8)$ \\
\hline \multicolumn{2}{|l|}{ Marital status } \\
\hline Partner/spouse, n (\%) & $228(46.3)$ \\
\hline Single, n (\%) & $196(39.8)$ \\
\hline Unknown, n (\%) & $68(13.8)$ \\
\hline \multicolumn{2}{|l|}{ Informal care at home, (\%) } \\
\hline No, n (\%) & $280(56.9)$ \\
\hline Yes, n (\%) & $212(43.1)$ \\
\hline \multicolumn{2}{|l|}{ Specialties involved in the ED, (\%) } \\
\hline $1, \mathrm{n}(\%)$ & $378(76.8)$ \\
\hline$>1, \mathrm{n}(\%)$ & $114(23.2)$ \\
\hline
\end{tabular}

${ }^{*}$ Based on the urgency levels 1 (life threatening) and 2 (emergent) of the Netherlands Triage System (NTS).

†Based on the urgency levels 3 (urgent), 4 (non-urgent) and 5 (advice) of the NTS.

fBetween 06:01 and 18:00.

§Between 18:01 and 06:00.

|Between Friday 18:01 and Sunday 12:00.

${ }^{* *} \geq 5$ different types of medicines.

$\mathrm{CCl}$, Charlson Comorbidity Index; ED, emergency department.

therapeutic or diagnostic interventions were planned for the patient's initial problem except from diagnostics normally conducted at the ED or (3) the patient's initial problem could have been prevented or avoided by timely recognition of needs and provision of care prior to admission. These three assessment criteria are derived from previous publications defining the concept of a preventable admission. ${ }^{2} 51011$ Individual assessments were compared by researchers and in any case of disagreement, a third researcher (ie, an experienced geriatrician) was consulted.

\section{Identification of physicians' perceived causes for PEAs}

For each identified PEA, MV and SvdB approached the physician responsible for the admission (eg, the resident or specialist) within 1-3 days after admission. A standardised set of open questions was used to identify perceived causes for admission: (1) What was the most important reason to admit this patient? (2) Could the patient have been send home safely/could hospitalisation have been prevented or avoided? (3) If so, what was needed to discharge the patient safely from the ED? Physicians were first approached and asked to answer the questions via email. Non-responders were subsequently contacted by telephone. Notes were made of the telephone conversations and relevant quotes were transcribed verbatim.

\section{Data analysis}

Descriptive analyses were performed to describe our study sample. Inter-rater reliability (Cohen's kappa) scores were calculated for the identified PEAs per study site. Because of the hierarchical structure of our study with patients nested within hospitals, we performed multilevel (mixed model) analyses. In this analyses, we take account of the variability associated with each level of nesting. We used a model with a random intercept and fixed parameters for all other variables. Multilevel univariate logistic regression analyses were performed to identify possible associations between PEAs and sociodemographic, clinical and care process factors. Fueled by previous literature questioning the validity of our third PEA assessment criterion, ${ }^{34} 35$ we also performed similar analyses to identify associative factors for emergency admissions that were classified as preventable based on criterion one or two. Factors with a significance of $\mathrm{p} \leq 0.20$ in the univariate regression analyses were then entered into a multilevel multivariate analysis. We then performed multivariate logistic regression with stepwise backward elimination. A $p$ value of $<0.05$ was considered to be statistically significant, based on two sided tests.

Physician's answers to the open questions (ie, email content, interview notes and verbatim quotes) were analysed according to the principles of thematic content analysis. ${ }^{36}$ At both study sites, relevant text fragments were coded. Codes were then grouped into conceptual (sub) themes on perceived causes. After multiple iterative rounds and reaching data saturation, researchers first identified (sub) themes per study site. Finally, overarching (sub) themes across both sites were identified.

\section{Patient and public involvement}

There were no patients involved in the design of this study 


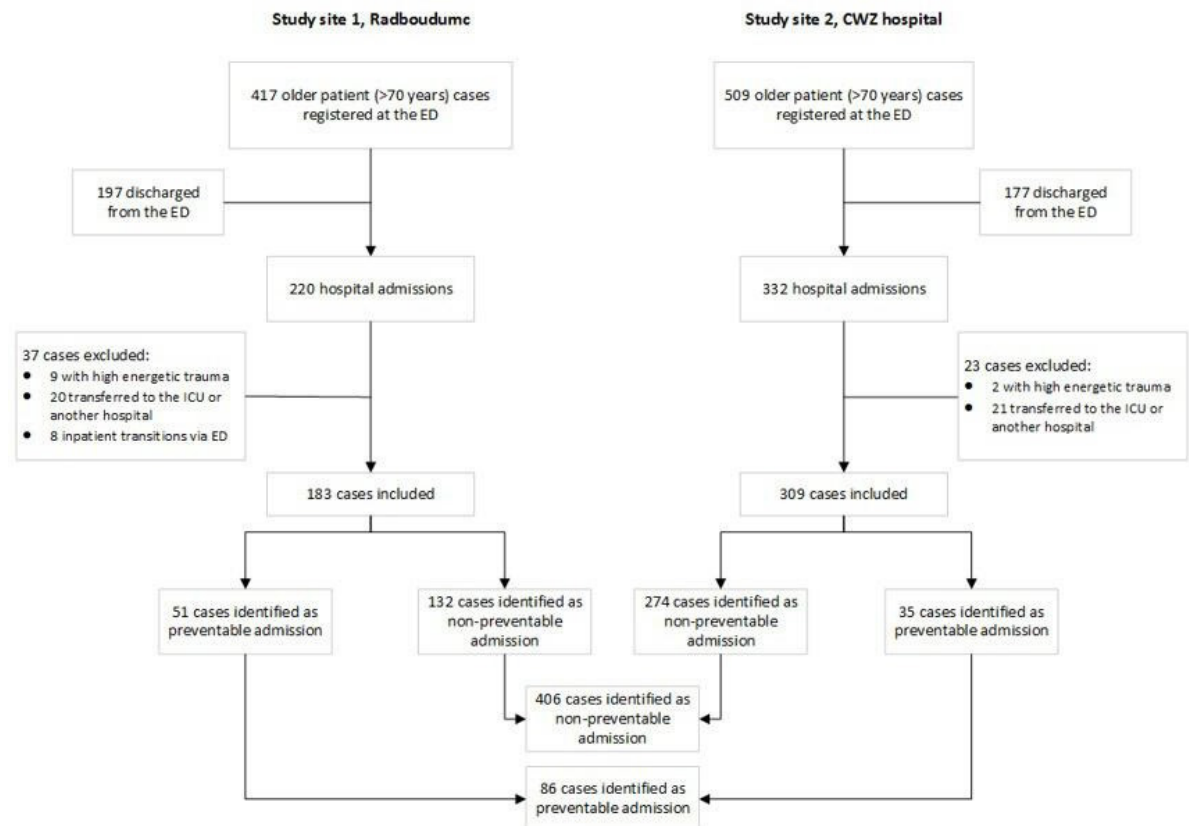

Figure 1 Flow chart of the study sample selection process. ED, emergency department; ICU, intensive care unit.

\section{RESULTS}

\section{Study sample}

In total 492 cases were included in the study: 183 in the Radboudumc and 309 in the CWZ hospital. A relatively small proportion of the cases, $4 \%$ and $5 \%$, respectively, consisted of patients who visited the ED twice. Overall, 60 cases were excluded from the study due to various reasons (figure 1). Sample characteristics are described in table 1.

\section{Prevalence of and associative factors for PEAs \\ Prevalence}

Overall, $86(17.5 \%)$ of the emergency admissions of older adults were identified as preventable (table 2). Most emergency admissions were identified as preventable, because the patient's initial problem could have been prevented or avoided by timely recognition of needs and provision of care prior to admission (criterion 3), and because no therapeutic or diagnostic intervention took place during hospitalisation (criterion 2). Inter-rater agreement of identified PEAs was moderate with a kappa of 0.5 at both study sites.

\section{Associative factors}

Univariate regression analysis showed that patients with a higher age (OR 1.04, 95\% CI 1.01 to $1.08 ; \mathrm{p}=0.02$ ) and a

Table 2 Proportion of preventable emergency admissions $(n=86)$ per definition criteria

\begin{tabular}{ll}
\hline Criterion & N (\%) \\
\hline 1. No somatic causes & $8(9.3)$ \\
$\begin{array}{l}\text { 2. No diagnostic or therapeutic interventions } \\
\begin{array}{l}\text { 3. No timely recognition of needs and care } \\
\text { provision }\end{array}\end{array}$ & $52(60.5)$ \\
\hline
\end{tabular}

low urgency classification (OR 1.78, 95\% CI 1.08 to 2.92; $\mathrm{p}=0.02$ ) were significantly associated with an increased likelihood of experiencing a PEA (table 3). Attending the ED in the weekend (OR 1.89, 95\% CI 1.15 to $3.11 ; \mathrm{p}=0.01$ ) and being single (OR 1.70, 95\% CI 1.02 to 2.83; $\mathrm{p}=0.04$ ) were also significantly associated with an increased likelihood of a PEA. The multivariate regression found three associative factor for PEAs: patients with higher age (adjusted OR 1.04, 95\% CI 1.01 to 1.08; $\mathrm{p}=0.04$ ), patients with a low urgency classification (adjusted OR 1.89, 95\% CI 1.14 to $3.15 ; \mathrm{p}=0.01$ ), and patients attending the ED in the weekend (adjusted OR 2.02, 95\% CI 1.22 to 3.37; $\mathrm{p}<0.01$ ). Except for a low urgency classification, the same associative factors were found for the admissions classified as preventable only on the basis of assessment criterion one or two: patients with a higher age (adjusted OR $1.04,95 \%$ CI 1.01 to $1.08 ; \mathrm{p}=0.02$ ) and patients attending the ED in the weekend (adjusted OR 1.86, 95\% CI 1.13 to 3.07; $\mathrm{p}=0.02$; supplement 2).

\section{Perceived causes for PEAs}

Forty-nine physicians-varying in gender, specialty, function and professional experience (online supplementary file 3)-were interviewed for one or multiple admission cases. In total, 86 unique PEA cases were discussed. Perceived causes for PEAs were categorised into six themes: (1) patient self-management, (2) decision for admission based on patient's social context and moral grounds (ie, what is right and wrong to do), (3) poor anticipation to health problems by professionals in the outpatient setting, (4) delayed access to diagnostic resources in the hospital, (5) limited access to community care resources out of hours, and (6) lack of patientspecific information at the ED. 
Table 3 Univariate and multivariate logistic regression analysis of variables associated with preventable emergency admissions

\begin{tabular}{|c|c|c|c|c|c|c|}
\hline \multirow[b]{2}{*}{ Independent variable } & \multirow{2}{*}{$\begin{array}{l}\text { Preventable } \\
\text { admissions }\end{array}$} & \multirow{2}{*}{$\begin{array}{l}\text { Non- } \\
\text { preventable } \\
\text { admission }\end{array}$} & \multicolumn{2}{|l|}{ Univariate analysis } & \multicolumn{2}{|c|}{ Multivariate analysis } \\
\hline & & & OR (95\% Cl) & $P$ value & OR $(95 \% \mathrm{Cl})$ & $P$ value \\
\hline Age, mean years (SD) & $80.2(6.7)$ & $78.9(6.7)$ & 1.04 (1.01 to 1.08$)$ & 0.02 & 1.04 (1.00 to 1.08$)$ & 0.04 \\
\hline $\operatorname{Sex}(\%)$ & & & & 0.04 & & \\
\hline Male (ref) & 13.9 & 86.1 & 1 & & & \\
\hline Female & 20.6 & 79.4 & 1.69 (1.04 to 2.77$)$ & & & \\
\hline \multicolumn{7}{|l|}{ ED referral (\%) } \\
\hline By physician or ambulance & 16.0 & 79.0 & 1 & 0.24 & & \\
\hline By patient self & 21.0 & 84.0 & 1.35 (0.81 to 2.24$)$ & & & \\
\hline Urgency, (\%) & & & & 0.02 & & \\
\hline High urgency* (ref) & 15.3 & 84.7 & 1 & & 1 & \\
\hline Low urgency† & 19.9 & 80.1 & 1.78 (1.08 to 2.92$)$ & & 1.89 (1.14 to 3.15$)$ & 0.01 \\
\hline Time of arrival, (\%) & & & & 0.78 & & \\
\hline Office hoursł (ref) & 17.6 & 82.4 & 1 & & & \\
\hline Out of hours§ & 17.3 & 82.7 & 0.93 (0.56 to 1.54$)$ & & & \\
\hline Day of arrival, (\%) & & & & 0.01 & & \\
\hline Weekdays (ref) & 14.4 & 85.6 & 1 & & 1 & \\
\hline Weekendף & 25.5 & 74.5 & 1.89 (1.15 to 3.11$)$ & & 2.02 (1.22 to 3.37 ) & $<0.01$ \\
\hline Polypharmacy**, (\%) & & & & 0.25 & & \\
\hline No (ref) & 14.2 & 85.8 & 1 & & & \\
\hline Yes & 18.4 & 81.6 & 1.43 (0.77 to 2.66$)$ & & & \\
\hline $\mathrm{CCl}$, mean (SD) & $5.93(1.8)$ & $5.97(2.2)$ & 0.99 (0.89 to 1.11$)$ & 0.89 & & \\
\hline $\begin{array}{l}\text { ED length of stay, mean } \\
\text { minutes (SD) }\end{array}$ & $243.6(95.0)$ & $219.2(96.7)$ & 1.00 (1.00 to 1.00$)$ & 0.32 & & \\
\hline Marital status, (\%) & & & & 0.04 & & \\
\hline Partner/spouse (ref) & 15.0 & 85.0 & 1 & & & \\
\hline Single & 22.2 & 77.8 & 1.70 (1.02 to 2.83$)$ & & & \\
\hline Informal care at home, (\%) & & & & 0.24 & & \\
\hline No (ref) & 11.8 & 88.2 & 1 & & & \\
\hline Yes & 25.0 & 75.0 & 1.47 (0.77 to 2.79$)$ & & & \\
\hline $\begin{array}{l}\text { Specialties involved at the ED, } \\
(\%)\end{array}$ & & & & 0.13 & & \\
\hline 1 (ref) & 15.9 & 84.1 & 1 & & & \\
\hline$>1$ & 22.8 & 77.2 & 1.51 (0.89 to 2.56$)$ & & & \\
\hline
\end{tabular}

*Based on the urgency levels 1 (life threatening) and 2 (emergent) of the Netherlands Triage System (NTS).

†Based on the urgency levels 3 (Urgent), 4 (Non-urgent) and 5 (Advice) of the NTS.

‡Between 06:01 and 18:00.

§Between 18:01 and 06:00.

|Between Friday 18:01 and Sunday 12:00.

${ }^{\star *}$ Five different types of medicines.

$\mathrm{CCl}$, Charlson Comorbidity Index; ED, emergency department.

Theme 1: patient self-management

Many of the treating physicians argued that patients who were discharged from the hospital often lacked important information about regulating their disease and managing their life-style at home. According to the physicians, admissions from the ED could have been avoided if patients were better instructed at discharge on self-care tasks.

Physicians also mentioned that several PEAs were rooted in the patient's late request for medical help or care support at home. Patients postpone their visit to their general practitioner (GP) and the GP out of hours 
service until hospitalisation is unavoidable. These admissions could have been avoided if the initial problem was addressed earlier.

If this patient [suffering from progressive dyspnoea due to decompensated heart failure] had visited his GP or called our outpatient clinic, we could have made timely alterations in his medication and prevent the admission.-Cardiologist, CWZ hospital

\section{Theme 2: decision for admission based on patient's social context} and moral grounds

Physicians felt that they were sometimes persuaded by the explicit wish or pressure from patients and relatives to admit the patient from the ED while admission was not needed from a medical point of view.

There was an explicit wish of the patient [with suspected hemoptysis and abdominal pain] and her relatives to observe her health condition overnight and to perform more diagnostics via a thoracic CT. The patient could have been discharged from the ED to home if she and her relatives hadn't had this wish.Pulmonologist, Radboudumc

It also occurred that physicians chose for admission based on moral grounds. Empathy with the personal situation of patients and relatives (eg, lack of transport to home, and stress about managing self-care and home support), and with patients attending the ED in the evening and at night made them decide to admit patients, even if there was no medical need.

Theme 3: poor anticipation to health problems by professionals in the outpatient setting

According to several physicians, the admissions of patients attending the ED with acute chronic health problems (eg, chronic anaemia) could have been prevented if deteriorations and exacerbations were recognised in time by providers in the community and treated in outpatient day-care settings (eg, blood transfusions for patients with chronic anaemia).

The patient suffered from chronic anaemia, which was progressive over time. More timely recognition or more frequent monitoring could have prevented the symptomatic anaemia for which this patient was admitted.-Internist, CWZ hospital.

\section{Theme 4: delayed access to diagnostic resources in the hospital}

The delayed access to diagnostics and imaging resources, such as performing a CT angiography, also triggered several physicians from both hospitals to admit patients from the ED. These situations occurred especially during evening hours. Patients were then hospitalised in anticipation of further diagnostics on the next day, while the overnight hospital stay was not needed from the physician's medical point of view.
We are often confronted with cases where we don't seriously suspect a pulmonary embolism, but we do see an elevated d-dimer and therefore need to scan these patients. If this cannot be done in the evening hours, patients are admitted to receive scans the next day. ED physician and resident Pulmonology, CWZ hospital

Theme 5: limited access to community care resources out of hours Physicians experienced difficulties with arranging timely and adequate follow-up (eg, rehabilitation care, home care, nursing home care) during out of hours. During these hours, they are often confronted with a limited number of available beds and professional support in the community. Physicians also mentioned having limited access to counterpart colleagues in the community during out of hours to discuss options for care support at home and to coordinate follow-up. As a result, they were more hesitant to discharge patients from the ED during these hours.

A lot of extra home care, revalidation or even nursing home care can be arranged during office hours. On the contrary, these options are severely limited in the evening and night.-Emergency Physician, CWZ hospital

\section{Theme 6: lack of patient-specific information at the ED}

Poor information about the living conditions and the available support at home hindered physicians at the ED in determining whether or not the patient could return to home. This lack of information often made them choose for the 'safest' option and admit the patient. Especially inexperienced residents were more inclined to admit patients in such situations.

Because of absence of family or friends at the ED or because of limited available time to investigate the patient's home situation, we cannot determine if the patient can return to home safely. (...) Such cases definitely result into admissions.-Internist, CWZ hospital

Physicians expressed that emergency admissions, particularly during out of hours, could have been avoided if preferences and wishes of terminally ill and frail older patients regarding hospital treatment and end-of-life care would have been formalised and accessible at the ED.

\section{DISCUSSION}

To our knowledge, this is the first study that assessed PEA rates, investigated factors associated with PEAs and explored physician perceived causes of PEAs at the individual older patient level. Overall, nearly one in five emergency admissions was classified as preventable. For nearly 1 in 10 cases, no somatic cause was found or medical interventions were performed during the time of admission. This corresponds with similar proportions of 
PEAs found in previous studies. ${ }^{10}{ }^{29}$ We found significant associations between PEAs and demographic, clinical and care process factors, which have not been identified as objective indicators for PEAs among older adults before. In contrast to previous studies, ${ }^{29}{ }^{37}$ higher age of older patients, a low urgency classification and ED attendance in the weekend was associated with an increased likelihood of a PEA after adjusting for confounding factors. We assume that a higher age, and an increased chance of comorbidities and atypical symptoms, may complicate the physician's clinical assessment, ${ }^{15}$ and make decisions to admit the patient possibly more sensitive for error. As older age is significantly associated with more emergency admissions we know that physicians often need to make such decisions. ${ }^{38}$ Previous studies showed that the mode (ie, ED attendance resulting from the lack of continuity with primary care physicians) and time of ED arrival are associated with an increased risk of admission. ${ }^{39-46}$ However, no studies have identified these characteristics as risk factors for PEAs of older adults before.

The context that hospital physicians described at the individual patient-level provided valuable in-depth insight into the causes for PEAs which cannot be retrieved by database or survey research. Most of our quantitative findings are supported and further explained by the qualitative findings. For example, the lack of caregiver support and community resources needed to maintain patients at home, and the limited access to community care resources during out of office hours were often described as important causes for admitting the older patient. While these are well-known causes for preventable admissions, ${ }^{211} 153047$ other causes found in this study have not been described before (ie, pressure by relatives to admit the patient during ED attendance) or were only described in a limited number of studies with little evidence (ie, postponement of medical care or support at home ${ }^{48}$ delayed access to inpatient diagnostic resources or services, ${ }^{30}$ and poor communication about treatment preferences of terminally ill and frail older patients at the primary care and hospital care interface ${ }^{49}{ }^{50}$ These findings complement existing literature describing other potential causes for PEAs, such as: work pressure, lack of professional experience, the pressure of not exceeding ED waiting targets and limited access to community care liaisons. ${ }^{29} 30$ Findings also show that causes for PEAs of older adults exist at various levels (ie, patient, provider, ED, hospital, primary care and hospital-primary care interface $^{29} 30$ and that many causes are manageable by policy-makers and providers.

Our study had several limitations. First, the relatively small sample size from two different types of EDs within one Dutch region limits the generalisability of our findings. Although this was a limiting factor, we deliberately chose to use research time and capacity to perform a multi-method in-depth inquiry. This allowed us to capture case experiences, understand underlying causes for PEAs, cross-check quantitative and qualitative data and increase the trustworthiness of our findings. ${ }^{51}{ }^{52}$ Moreover, the estimation of PEAs was fairly accurate with only a margin of error of $3 \%$. Second, findings on associative factors may be biased by the omission of relevant confounding variables that were unknown to us or because variable data were inaccessible (eg, social status) or difficult to retrieve. For example, we did not collect data on several variables related to $\mathrm{ED}$ crowding (eg, bed occupancy) and time pressure (eg, ED waiting time), while these variables are considered potentially important risk factors for PEAs. ${ }^{29}{ }^{30}$ Third, data were collected during specific season periods (eg, summer and fall). The number of admissions in this study may be underestimated as admission rates are generally higher in the winter. Fourth, classifications of PEAs were based on reviewer's judgements using case-specific information. This subjective approach introduces risk of individual bias, which may be reflected in the moderate inter-rater agreement scores and the $16.6 \%$ rate difference of PEA between study sites. In addition, reviewers were aware of the study purpose and may have been biased in terms of perceiving a need to reduce PEAs. This may have affected the found PEA rates. However, in the absence of validated protocols to identify PEAs, ${ }^{5053}$ a consensus-based judgement of individual cases by multiple reviewers with a clinical background was considered most appropriate to classify the admissions. Fifth, reviewers were emergency residents. Other (experienced) clinical perspectives therefore may have been under-represented in the classification process. Sixth, although derived from previous operationalisations, our definition of a PEA was not validated. Classifying admissions as preventable or avoidable remains subject of constant debate as there is no uniform and validated definition to directly identify such admissions. ${ }^{5853}$ The PEA rates found in this study may therefore be difficult to compare with rates found in other studies. Seventh, physicians' perceptions were collected in a consecutive order. Physicians were not purposively sampled on characteristics that could impact the risk of a PEA (eg, medical specialty, seniority and working experience) and these may therefore have been unremarked. ${ }^{29}{ }^{30}$ Lastly, including the perspectives of community care providers and patients themselves could also have contributed to a better understanding and trustworthiness of our findings. Via patients and community care providers (eg, the GP), we could have learnt much more about the added value or adverse consequences of the admission apart from whether or not is was preventable from a clinical perspective. Future studies investigating the magnitude and origin of PEAs therefore should include the perspective of patients, caregivers and their community health professionals.

Despite these limitations, we believe that the found PEA rates show that there is ample room to improve healthcare for older adults, in the right place and at lower costs. The identified associative factors and underlying causes for PEAs may guide policy-makers and providers in achieving these goals. Strategies must be further developed and disseminated that are helpful for hospital physicians in 
their everyday assessment of and decision to hospitalise older patients from the ED. For example, the introduction of ED-based liaison services responsible for exploring and coordinating outpatient care alternatives, educational programmes in geriatric EM, transmural protocols for timely organisation of (out of hours) rehabilitation care in the community and effective management of endof-life care, and tools for coping with ethical dilemmas, family pressure and time pressure in the ED. The involvement of the geriatrician in the decision-making process of admission in the ED could also help to reduce inappropriate admissions. Moreover, GPs, especially those working out of hours, need to be stimulated in finding outpatient solutions for older patients in need of social support and with exacerbations of chronic conditions that do not require specialist care.

In conclusion, our study findings contribute to existing evidence that many emergency admissions of older adults are preventable, thereby demonstrating a possible source of unnecessary expensive, and potentially harmful, hospital care. Found insights into physician perceived causes may provide clues for reducing PEAs among the ever-increasing older patient population. Further research is however warranted to extrapolate these findings and test the effectiveness of strategies aimed at reducing PEAs of older adults.

\section{Author affiliations \\ ${ }^{1}$ Emergency Department, Canisius Wilhelmina Hospital, Nijmegen, Netherlands ${ }^{2}$ Emergency Department, Radboudumc, Nijmegen, Gelderland, Netherlands ${ }^{3}$ Department of Primary and Community Care, Radboudumc, Nijmegen, Gelderland, Netherlands \\ ${ }^{4}$ Scientific Institute for Quality of Healthcare (IQ healthcare), Radboud University Medical Center, Nijmegen, Netherlands \\ ${ }^{5}$ Department of Geriatrics, Radboudumc, Nijmegen, Gelderland, Netherlands}

Contributors GH and YS designed the study. MV and SvdB acquired the data. $\mathrm{SvdB}$ and GH performed the analyses. NH and LvW performed secondary assessment of data. All authors were involved in interpretation of data. SvdB and GH wrote the first draft of the manuscript. All authors were involved in revisions and approving the final manuscript for publication. SvdB is guarantor for the manuscript.

Funding The authors have not declared a specific grant for this research from any funding agency in the public, commercial or not-for-profit sectors.

Competing interests None declared.

Patient consent for publication Not required.

Ethics approval The local ethics commission (CMO Arnhem-Nijmegen region) approved the study (registration number: 2018-4527).

Provenance and peer review Not commissioned; externally peer reviewed.

Data availability statement The data that support the findings of this study (database with variables in SPSS) are available from the corresponding author, upon reasonable request.

Supplemental material This content has been supplied by the author(s). It has not been vetted by BMJ Publishing Group Limited (BMJ) and may not have been peer-reviewed. Any opinions or recommendations discussed are solely those of the author(s) and are not endorsed by BMJ. BMJ disclaims all liability and responsibility arising from any reliance placed on the content. Where the content includes any translated material, BMJ does not warrant the accuracy and reliability of the translations (including but not limited to local regulations, clinical guidelines, terminology, drug names and drug dosages), and is not responsible for any error and/or omissions arising from translation and adaptation or otherwise.
Open access This is an open access article distributed in accordance with the Creative Commons Attribution Non Commercial (CC BY-NC 4.0) license, which permits others to distribute, remix, adapt, build upon this work non-commercially, and license their derivative works on different terms, provided the original work is properly cited, appropriate credit is given, any changes made indicated, and the use is non-commercial. See: http://creativecommons.org/licenses/by-nc/4.0/.

\section{ORCID iDs}

Steef van den Broek http://orcid.org/0000-0002-7775-4869

Yvonne Schoon http://orcid.org/0000-0002-8482-9048

Gijs Hesselink http://orcid.org/0000-0003-2532-0724

\section{REFERENCES}

1 Wachelder JJH, Stassen PM, Hubens LPAM, et al. Elderly emergency patients presenting with non-specific complaints: characteristics and outcomes. PLoS One 2017;12:e0188954

2 O'Cathain A, Knowles E, Maheswaran R, et al. A system-wide approach to explaining variation in potentially avoidable emergency admissions: national ecological study. BMJ Qual Saf 2014;23:47-55.

3 Morley C, Unwin M, Peterson GM, et al. Emergency department crowding: a systematic review of causes, consequences and solutions. PLoS One 2018;13:e0203316.

4 Barker I, Steventon A, Deeny SR. Association between continuity of care in general practice and hospital admissions for ambulatory care sensitive conditions: cross sectional study of routinely collected, person level data. BMJ 2017;356:j84.

5 Purdey S, Huntley A. Predicting and preventing avoidable hospital admissions: a review. J R Coll Physicians Edinb 2013;43:340-4.

6 Lynch B, Fitzgerald AP, Corcoran P, et al. Drivers of potentially avoidable emergency admissions in Ireland: an ecological analysis. BMJ Qual Saf 2019;28:438-48.

7 Rosano A, Loha CA, Falvo R, et al. The relationship between avoidable hospitalization and accessibility to primary care: a systematic review. Eur J Public Health 2013;23:356-60.

8 Purdy S, Griffin T, Salisbury C, et al. Ambulatory care sensitive conditions: terminology and disease coding need to be more specific to aid policy makers and clinicians. Public Health 2009;123:169-73.

9 Torjesen I. Almost 1.5m emergency hospital admissions could have been avoided last year. BMJ 2018;361:k2542.

10 Steventon A, Deeny S, Friebel R, et al. Briefing: emergency hospital admissions in England: which may be avoidable and how? London, UK: the health Foundation, 2018. Available: http://reader.health.org. uk/emergency-admissions

11 Solberg LI, Ohnsorg KA, Parker ED, et al. Potentially preventable hospital and emergency department events: lessons from a large innovation project. Perm J 2018;22:17-102.

12 Wolf D, Rhein C, Geschke K, et al. Preventable hospitalizations among older patients with cognitive impairments and dementia. Int Psychogeriatr 2019;31:383-91.

13 Lin P-J, Zhong Y, Fillit HM, et al. Hospitalizations for ambulatory care sensitive conditions and unplanned readmissions among Medicare beneficiaries with Alzheimer's disease. Alzheimers Dement 2017;13:1174-8.

14 Wolters A, Santos F, Lloyd T, et al. Emergency admissions to hospita from care homes: how often and what for? London, UK: the health Foundation, 2019. Available: https://www.health.org.uk/publications/ reports/emergency-admissions-to-hospital-from-care-homes

15 Samaras N, Chevalley T, Samaras D, et al. Older patients in the emergency department: a review. Ann Emerg Med 2010;56:261-9.

16 Blunt I. Focus on preventable admissions: trends in emergency admissions for ambulatory care sensitive conditions, 2001 to 2013. QualityWatch, 2013. Available: www.health.org.uk

17 Morganti KG, Bauhoff S, Blanchard JC, et al. The evolving role of emergency departments in the United States. Rand Health $Q$ 2013;3:3.

18 Moy E, Chang E, Barret M. Centers for Disease Control and Prevention (CDC). Potentially preventable hospitalizations - United States, 2001-2009. MMWR Suppl 2013;62:139-43.

19 Vivanti AP, McDonald CK, Palmer MA, et al. Malnutrition associated with increased risk of frail mechanical falls among older people presenting to an emergency department. Emerg Med Australas 2009;21:386-94.

20 Joseph B, Phelan H, Hassan A, et al. The impact of frailty on failureto-rescue in geriatric trauma patients: a prospective study. $J$ Trauma Acute Care Surg 2016;81:1150-5.

21 Ouslander JG, Maslow K. Geriatrics and the triple AIM: defining preventable hospitalizations in the long-term care population. J Am Geriatr Soc 2012;60:2313-8. 
22 Covinsky KE, Palmer RM, Fortinsky RH, et al. Loss of independence in activities of daily living in older adults hospitalized with medical illnesses: increased vulnerability with age. J Am Geriatr Soc 2003;51:451-8.

23 Bindman AB, Grumbach K, Osmond D, et al. Preventable hospitalizations and access to health care. JAMA 1995;274:305-11.

24 Laditka JN, Laditka SB, Probst JC. More may be better: evidence of a negative relationship between physician supply and hospitalization for ambulatory care sensitive conditions. Health Serv Res 2005;40:1148-66.

25 Magán P, Alberquilla A, Otero A, et al. Hospitalizations for ambulatory care sensitive conditions and quality of primary care: their relation with socioeconomic and health care variables in the Madrid regional health service (Spain). Med Care 2011;49:17-23.

26 Purdy S, Griffin T, Salisbury C, et al. Emergency respiratory admissions: influence of practice, population and hospital factors. $J$ Health Serv Res Policy 2011;16:133-40.

27 Falster MO, Jorm LR, Douglas KA, et al. Sociodemographic and health characteristics, rather than primary care supply, are major drivers of geographic variation in preventable hospitalizations in Australia. Med Care 2015;53:436-45.

28 Paul MC, Dik J-WH, Hoekstra T, et al. Admissions for ambulatory care sensitive conditions: a national observational study in the general and COPD population. Eur J Public Health 2019;29:213-9.

29 Daniels LM, Sorita A, Kashiwagi DT, et al. Characterizing potentially preventable admissions: a mixed methods study of rates, associated factors, outcomes, and physician decision-making. J Gen Intern Med 2018;33:737-44.

30 Pope I, Burn H, Ismail SA, et al. A qualitative study exploring the factors influencing admission to hospital from the emergency department. BMJ Open 2017;7:e011543.

31 Bakker L, Kemper PF, Wagner C, et al. A baseline assessment by healthcare professionals of Dutch pharmacotherapeutic care for the elderly with polypharmacy. Eur J Public Health 2017;27:679-86.

32 Quan H, Li B, Couris CM, et al. Updating and validating the Charlson comorbidity index and score for risk adjustment in hospital discharge Abstracts using data from 6 countries. Am J Epidemiol 2011;173:676-82.

33 NTS. Netherlands triage system, 2009. Available: http://www.de-nts. $\mathrm{nl}$ [Accessed November 2019].

34 Solberg LI. Preventable hospital admissions: are they? Fam Pract 2015;32:245-6.

35 Johnston JJ, Longman JM, Ewald DP, et al. Validity of a tool designed to assess the preventability of potentially preventable hospitalizations for chronic conditions. Fam Pract 2019:1-5.

36 Braun V, Clarke V. Using thematic analysis in psychology. Qual Res Psychol 2006;3:77-101

37 Chan T, Arendts G, Stevens M. Variables that predict admission to hospital from an emergency department observation unit. Emerg Med Australas 2008;20:216-20.
38 Lillebo B, Dyrstad B, Grimsmo A. Avoidable emergency admissions? Emerg Med J 2013;30:707-11.

39 Kim SW, Li JY, Hakendorf P, et al. Predicting admission of patients by their presentation to the emergency department. Emerg Med Australas 2014;26:361-7.

40 Sun Y, Heng BH, Tay SY, et al. Predicting hospital admissions at emergency department triage using routine administrative data. Acad Emerg Med 2011;18:844-50.

41 Cameron A, Rodgers K, Ireland A, et al. A simple tool to predict admission at the time of triage. Emerg Med J 2015;32:174-9.

42 Blom MC, Jonsson F, Landin-Olsson M, et al. The probability of patients being admitted from the emergency department is negatively correlated to in-hospital bed occupancy - a registry study. Int J Emerg Med 2014;7:8.

43 Smith A, Dolan D, Mahmoud O. Does a busy emergency department have a lower threshold for referral to the acute medical team? The University of Manchester, 2020.

44 Pereira Gray D, Henley W, Chenore T, et al. What is the relationship between age and deprivation in influencing emergency hospital admissions? a model using data from a defined, comprehensive, allage cohort in East Devon, UK. BMJ Open 2017;7:e014045.

45 Baré ML, Prat A, Lledo L, et al. Appropriateness of admissions and hospitalization days in an acute-care teaching hospital. Revue d'épidémiologie et de santé publique 1995;43:328.

46 Kohnke H, Zielinski A. Association between continuity of care in Swedish primary care and emergency services utilisation: a population-based cross-sectional study. Scand J Prim Health Care 2017;35:113-9.

47 Ride J, Kasteridis P, Gutacher N, et al. Impact of continuity of family practice care in unplanned ED use and hospital admissions for patients with serious mental illness. Health Serv Res 2019;54:1316-25.

48 Chen $\mathrm{H}$, Walabyeki J, Johnson $\mathrm{M}$, et al. An integrated understanding of the complex drivers of emergency presentations and admissions in cancer patients: qualitative modelling of secondary-care health professionals' experiences and views. PLoS One 2019;14:e0216430.

49 McDermott C, Coppin R, Little P, et al. Hospital admissions from nursing homes: a qualitative study of GP decision making. $\mathrm{Br} J \mathrm{Gen}$ Pract 2012;62:e538-45.

50 Ouslander JG, Lamb G, Perloe M, et al. Potentially avoidable hospitalizations of nursing home residents: frequency, causes, and costs. J Am Geriatr Soc 2010;58:627-35

51 Hansen M, O'Brien K, Meckler G, et al. Understanding the value of mixed methods research: the children's safety Initiative-Emergency medical services. Emerg Med J 2016;33:489-94.

52 Tariq S, Woodman J. Using mixed methods in health research. JRSM Short Rep 2013;4:2042533313479197.

53 Gott M, Gardiner C, Ingleton C, et al. What is the extent of potentially avoidable admissions amongst hospital inpatients with palliative care needs? BMC Palliat Care 2013;12:9. 